\section{References}

Arnfield A. 2003. Two decades of urban climate research: a review of turbulence, exchanges of energy and water, and the urban heat island. Int. J. Climatol. 23

1-26.

Best MJ, Pryor M, Clark DB, Rooney GG, et al. 2011. The Joint UK Land

Environment Simulator (JULES), mode description - Part 1: energy and water fluxes. Geosci. Model. Dev. 4: 677-699.

Chang B, Wang H-Y, Peng T-Y, Hsu Y-S. 2010. Development and evaluation of a city-wide wireless weather sensor network. Educ. Technol. Soc. 13: 270-280.

Cheval S, Dumitrescu A. 2009. The July urban heat island of Bucharest as derived from MODIS images. Theor. Appl. Climatol. 96: $145-153$

Clark DB, Mercado LM, Sitch S, et al. 2011. The Joint UK Land Environment Simulator (JULES), model description Part 2: carbon fluxes and vegetation dynamics. Geosci. Model. Dev. 4: 701-722. Hung T, Uchihama D, Ochi S, Yasuoka Y. 2006. Assessment with satellite data of the urban heat island effects in Asian megacities. Int. J. Appl. Earth Obs. 8: $34-48$.

IEC. 2005. International Standard for Power Transformers, in Loading Guide for OilInmersed Power Transformers. International
Electrotechnical Commission (IEC):

Geneva, Switzerland.

Johnson D. 1985. Urban modification of diurnal temperature cycles in Birmingham U.K. Int. J. Climatol. 5: 221-225.

Jones PD, Kilsby CG, Harpham C, Glenis V, Burton A. 2009. UK Climate Projections Science Report: Projections of Future Daily Climate for the UK from the Weather Generator. University of Newcastle: Newcastle, UK.

Lindley SJ, Handley JF, Theuray N, Peet E, McEvoy D. 2006. Adaptation strategies for climate change in the urban environment: assessing climate change related risk in UK urban areas. J. Risk. Res. 9: 543-568.

Maxim PI. 2012. Temperature Logger iButton with 8KB Data-Log Memory. Maxim Integrated Products: Sunnyvale, CA, pp 1-52. http://www.maxim-ic.com/ datasheet/index.mvp/id/4088 (accessed 20 January 2012).

McCarthy MP, Best MJ, Betts RA. 2010. Climate change in cities due to global warming and urban effects. Geophys. Res. Lett. 37: L09705.

Oke TR. 1987. Boundary Layer Climates. Methuen: London.

Stewart I. 2010. A systematic review and scientific critique of methodology in modern urban heat island literature. Int. J. Climatol. 31: 200-217.
Tomlinson CJ, Chapman L, Thornes JE, Baker CJ. 2011a. Remote sensing land surface temperature for meteorology and climatology: a review. Meteorol. Appl.

18: 296-306.

Tomlinson CJ, Chapman L, Thornes JE, Baker CJ. 2011 b. Including the urban heat island in spatial heat health risk assessment strategies: a case study for Birmingham, UK. Int. J. Health Geogr. 10: 42. Tomlinson CJ, Chapman L, Thornes JE, Baker CJ. 2012a. Derivation of Birmingham's summer surface urban heat island from MODIS satellite images. Int. J. Climatol. 32: 214-224.

Tomlinson CJ, Chapman L, Thornes JE, Baker CJ, Prieto-Lopez T. 2012b.

Comparing night time satellite land surface temperature from MODIS and ground measured air temperature across a conurbation. Remote Sens. Lett. 3: 657-666.

United Nations. 2008. World urbanization prospects: the 2007 revision.

Unwin DJ. 1980. The synoptic climatology of Birmingham's urban heat island, 1965-74. Weather 35: 43-50.

Correspondence to: Charlie Tomlinson cjt512@bham.ac.uk (c) 2013 Royal Meteorological Society DOI: 10.1002/wea.1998

\title{
A low-cost experiment for determining raindrop size distribution
}

\section{Jordi Mazon' and Marta Viñas ${ }^{2}$

\author{
'Applied Physics Department, Technical \\ University of Catalonia, BarcelonaTech, \\ Spain \\ ${ }^{2}$ University of Barcelona, Spain
}

\section{Introduction}

Precipitation is usually classified as convective or stratiform. Convective precipitation is normally associated with cumulus and cumulonimbus clouds within which a significant vertical velocity keeps the cloud droplets inside the cloud, enhancing their growth until the vertical currents are not able to counteract the force of gravity any longer and precipitation is produced.
Stratiform precipitation is produced mainly by nimbostratus and sometimes by stratocumulus/altocumulus. In these clouds the vertical velocity is lower than inside the convective clouds, and it cannot prevent cloud droplets from falling earlier. The result is a smaller raindrop in these clouds (Houze, 1993).

Drop Size Distribution (DSD) at ground level will depend, among other parameters, on the type of precipitation. It is known that DSD varies both spatially and temporally (Ulbrich, 1983), not only within a specific storm type but also across differing storm types and climatic regimes. It can be characterized by three parameters: diameter of the drops, their concentration, and the shape of the distribution. Several authors have analysed different DSDs in different rainfall regimes. Marshall and Palmer (1948) proposed an exponential function for DSD according to the analysis of two measured datasets. This exponential fit of the DSD tends to overestimate the number of both the smallest and largest drops (Joss et al., 1978). Since then, more sophisticated formulations have appeared: gamma, log normal, or Weibull distribution functions. All these functions make the assumption that several variables govern the DSD, with rain intensity being the most important given that the data are collected at ground level.

Several authors have used a gamma distribution to model raindrop size distribution (e.g. Ulbrich, 1983; Kozu et al., 1991; Smith, 1993; Zhang et al., 2001; Bringi et al., 2003). Others, like Feingold and Levin (1986), used a log-normal distribution as the best fit to 
DSD. However, observed data shows that sometimes the distribution of raindrop size is much more complex (Smith, 2003). Willis (1984) studied five distributions obtained in two tropical cyclones: three were fitted by using a Marshall-Palmer distribution function and two by using a gamma distribution function. The success of the fit was evaluated based on square errors, on coalescence growth error and on drop evaporation error. The coalescence growth and drop evaporation were computed by using microphysical models, and it was found that the gamma distribution function fit was the best compromise between satisfactory squared-error fit and the realistic characterization of coalescence growth and drop evaporation. Radhakrishna et al. (2008) studied mesoscale systems in India and showed, by using radar images, drop size distributions with two, three and more peaks during the transition period from convective to stratiform rain. This distribution was observed first above the freezing level in the presence of heavy rainfall; the two peaks of rain distribution were observed below the freezing level and, thus, are attributed to the coexistence of ice and supercooled droplets. Finally, the multipeak distribution was detected during the transition period as the rainfall intensity declined.

There are two main goals for this paper. First, we aim to give an example of a low cost and relatively accurate scientific experiment, well-suited to students of scientific subjects during the last year of secondary school and in the first year of degree courses in physics or mathematics. Although the experiment is based on the use of cheap materials that are easily acquired, it still allows students to obtain good data that is useful in achieving and understanding the precipitation process and to answer questions such as: are all raindrops equal in size? Secondly, we want to show some of the results obtained during the two years of our experiments, including how we analyzed and processed the data so as to offer a physical explanation for the results.

\section{The experimental method}

Disdrometers are the electronic devices used in many centres of research and many universities around the world to measure raindrop diameter. The raindrops are collected in a cylinder in which infrared beams detect the shallowness of the raindrops and a computer application transforms the diameter. These devices even measure the kinetic energy of the raindrops, which allows scientists to study other aspects of rainfall and on the soil (such as erosion) and on vegetation.

However, these devices are expensive, so are not really suitable for schools. Moreover, in the last year of school, and even in the first year of some scientific degrees, it could be more interesting to use other approaches that allow us to practise several topics about the scientific method, such as constancy, precision and rigour in measuring. This is the case with the methodology used in our experiment, adapted from those realised and described in Laws and Parson (1943). A $0.5 \mathrm{~m}^{2}$ platform is set up to collect raindrops: it is covered with flour, about $3 \mathrm{~cm}$ thick, and when raindrops hit it they adopt a spherical shape and do not evaporate (Figure 1). A few minutes after the precipitation episode begins, the platform is placed under the rain, on up to three occasions, for ninety seconds. This makes it easy to accurately measure the diameter of the raindrops by using an electronic sliding caliper with an accuracy of $+/-0.1 \mathrm{~mm}$ (Figure 2 ). The number of raindrops hitting the platform is variable, depending on the type of precipitation, but around 200 was a typical number of hits during the experiments.

Some of the experimental data collected by the high school students (from September 2008 to August 2010) has been plotted in histograms to analyse the raindrop size distribution. During this period the main data was collected in autumn (16 events) and spring (11 events), as these are the seasons of higher precipitation in the Mediterranean climate. During summer, the dry season, data was collected from only seven events, and there were eight events in winter, a season when most precipitation in the area is of weak intensity. In addition to collecting data about raindrop size, cloud type was observed and measurements were made of the amount of precipitation collected by the rain gauge during the events.

Measuring raindrop size in each precipitation event and plotting the histogram of the raindrop size distribution is a good exercise and practice for students in their last year at school (aged from 15 to 17). In addition, at higher academic levels, for instance during the first year of a physics degree (aged 18-20), it would be good practice to adjust the experimental data to a log-normal function.

By using this easy and cheap methodology, students are able to build their own

(a)

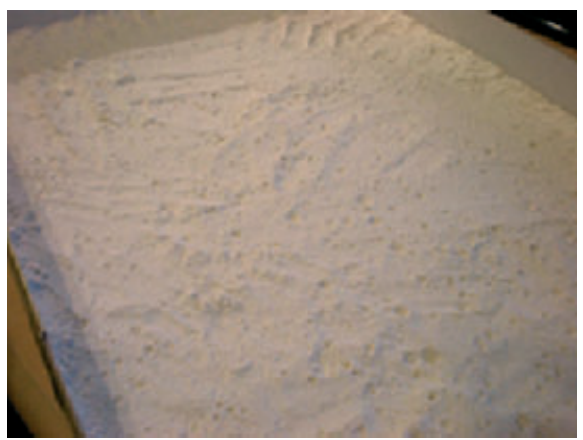

(b)

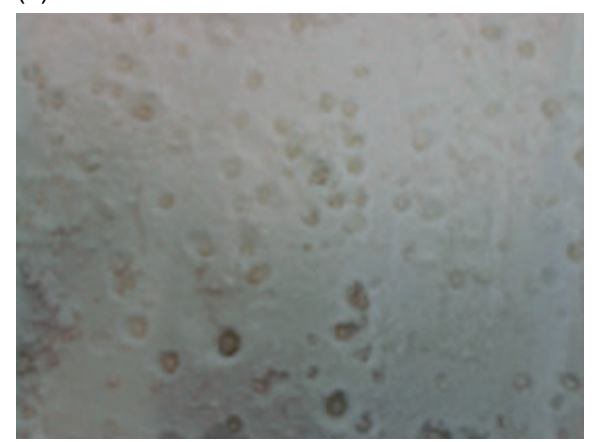

experimental method, measure droplet diameters, and find the mathematical function that best fits the readings.

\section{Results}

Figure 3(a) shows an example of the DSD histogram measured on 7 September 2009. This was a convective rainfall event, and $14 \mathrm{~mm}$ was measured in 30 minutes. The NOAA/NCEP reanalysis (not shown) of the synoptic situation at 0000 UTC on the 7th indicates weak troughing at the surface and 500 mbar, a typical scenario for heavy showers at this time of year along the coast of northeast Spain as the sea surface temperature is around $26^{\circ} \mathrm{C}$. The highest hit count on the flour-covered platform was for raindrops with diameters ranging from 1.5 to $2 \mathrm{~mm}$ : around 75 raindrops out of the 203 recorded, $37 \%$ of the total. Small raindrops of less than $0.5 \mathrm{~mm}$ in diameter were also measured ( $0.9 \%$ of the total), as well as large ones of more than $3.5 \mathrm{~mm}$ (1.8\%). The shape of this histogram is typical of those throughout the two years of the experiment. Figure $3 \mathrm{~b}$ shows the excellent log-normal fit adjusted to the experimental data.

The peak of the histogram indicates larger diameters throughout late spring, summer and early autumn because precipitation is mainly convective during these months; in some winter events the peak shifts to small droplets as these are associated with strati-

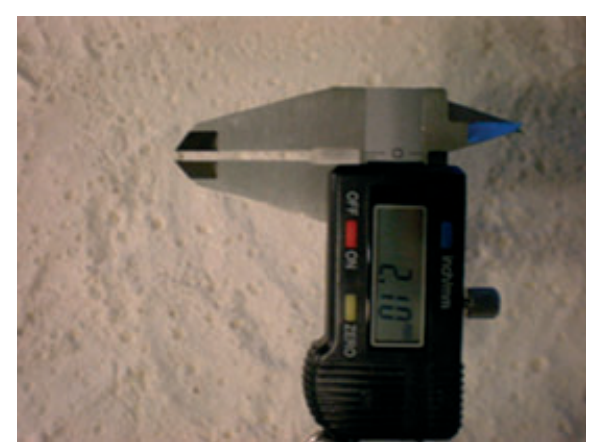

Figure 2. Measuring a raindrop on the flour-covered platform using an electronic sliding caliper.

Figure 1. A platform covered by flour: (a) after a rainfall event with many raindrop hits; (b) the raindrops adopt a spherical shape when hitting the flour. 
(a)

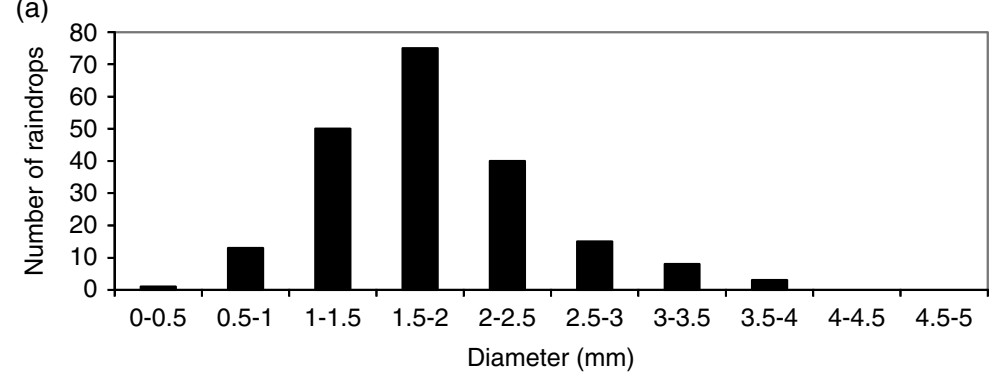

(b)

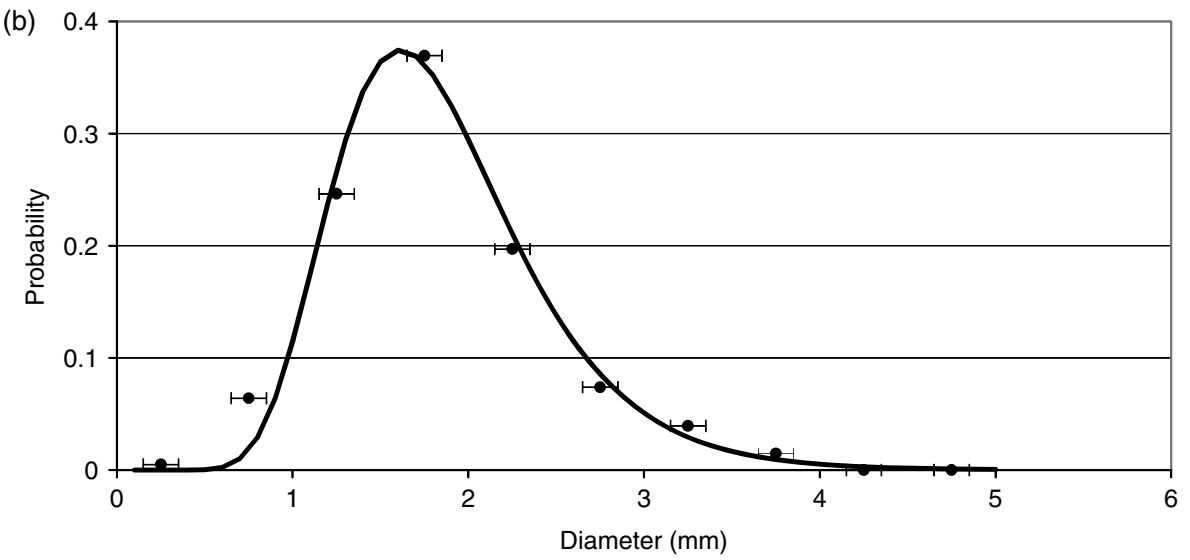

Figure 3. (a) Raindrop diameter histogram and (b) log-normal fit for the precipitation event on 7 September 2009.
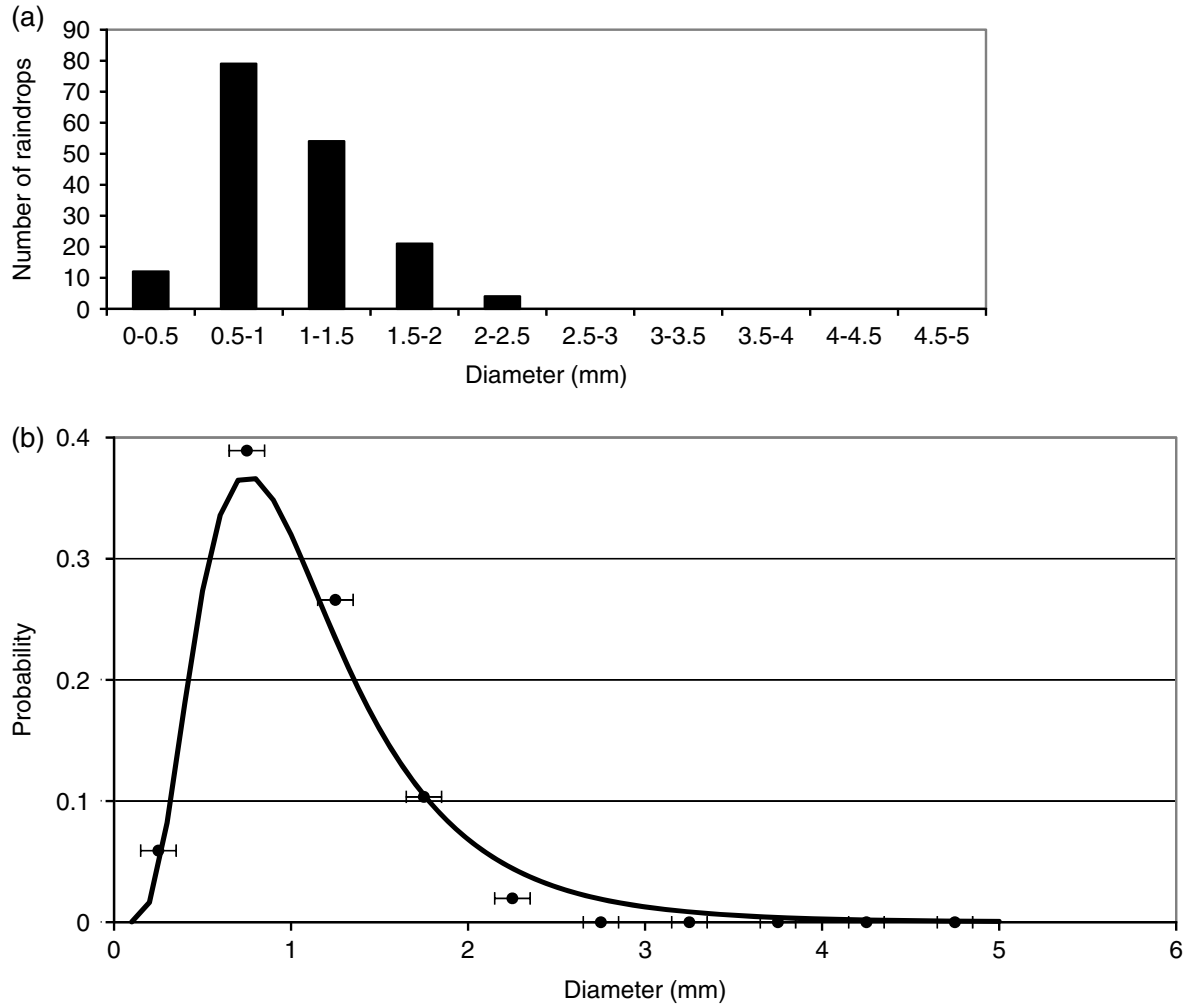

Figure 4. (a) Raindrop diameter histogram and (b) log-normal fit for the precipitation event on 21 December 2009.

form clouds in which the upward motion is weak. Figure 4 shows an example of the event recorded on 21 December 2009, in which the DSD peak is centred in the 0.5$1 \mathrm{~mm}$ range (79 hits out of 180 , or $39 \%$ ). On this date a cold front moved northeast across the Iberian Peninsula, a typical winter situation in which precipitation is usually weak in the Barcelona area. Stratocumulus clouds were observed and $5.4 \mathrm{~mm}$ of precipitation was measured during the morning.

It is important to take into account that this methodology is not able to record the smallest raindrops: those with a diameter below $0.5 \mathrm{~mm}$ that hit the floured platform are very difficult to detect. Thus, the number of raindrops hitting the platform is probably higher than recorded because a certain number simply cannot be measured.

Overall, the greatest number of raindrops has a diameter around $1 \mathrm{~mm}$ in winter and up to $4 \mathrm{~mm}$ in summer; the log-normal distribution usually works well along this spectrum. However, there were two episodes in 2010 in which the best fit to raindrop size was a bimodal log-normal. We illustrate here the first of these, on 30 May: Figure 5(a) shows the main peak centred between 1.5 and $2 \mathrm{~mm}$ ( $32 \%$ of all hits) with a secondary peak between 3.5 and $4 \mathrm{~mm}$ (10\%). Both convective and stratiform clouds were reported during this event. A weak cold front was drifting south over Spain and was giving light rain, but strong solar radiation around it released instability that led to the growth of convective clouds and the development of thundery activity: $23 \mathrm{~mm}$ was recorded in an hour. Thus the measured precipitation was due to different cloud types: cumulonimbus, with large raindrop size, and stratocumulus, with small raindrop size. This coexistence of clouds is more common in this period than in other seasons. Figure 5(b) shows the lognormal adjustment to the experimental data. The superposition of two log-normal functions constitutes an excellent adjustment to the experimental data. A similar result was found by Radhakrishna et al. (2008), who used radar images to study heavy rainfall episodes in India and proposed a similar hypothesis to explain DSD shape.

\section{Conclusions}

By using low-cost materials and an easy methodology, we have studied raindrop size distribution and found that the log-normal best fits the experimental data. This methodology is sufficiently precise and easy to understand - and it is cheap, which makes it appropriate for use in basic secondary school physics courses and even in the first year of some degrees, at a time when financial resources are under pressure in many education establishments. It allows high school students, teachers and meteorological amateurs to obtain interesting, low-cost conclusions about the precipitation process. In addition, the proposed methodology is applicable to different academic levels and several subjects (mathematics, physics, natural sciences, technology). Depending on the academic level, complexity can be increased. For example, the students who are halfway through high school can build the experimental set and measure the raindrops, which will introduce rigour and discipline in their measurements. In the last year of high school, students can plot the histograms and analyse the results, which 
(a)

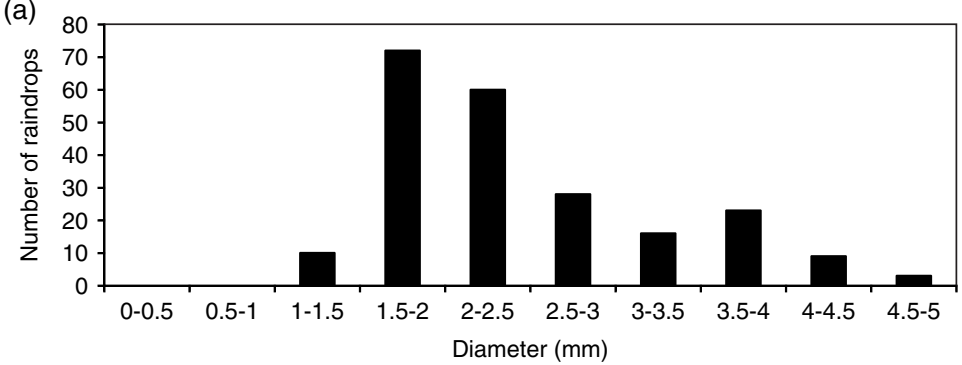

(b)

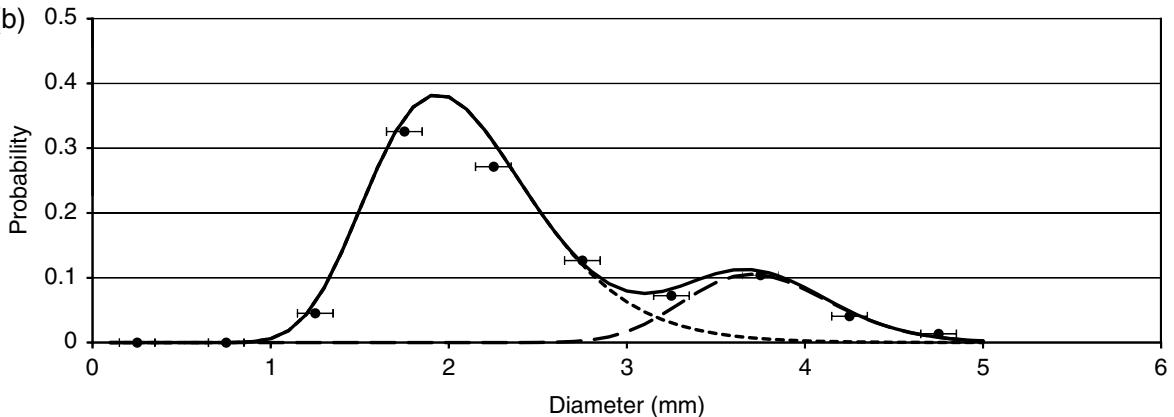

Figure 5. (a) Raindrop diameter histogram and (b) log-normal fit for the precipitation event on 30 May 2010. The log-normal function is drawn to fit all the measured raindrops (solid line), the smallest (long dashed line) and the largest (short dashed line) raindrops.

will help them to learn more about atmospheric phenomena by taking into account more information about the physical processes inside clouds. In the first year of university, or even in the last year of high school, students can obtain the log-normal function in order to fit the experimental data obtained.

We are aware that the employed methodology has serious limitations for a more detailed study of the distribution of raindrops. For example, what happens with drops below $0.5 \mathrm{~mm}$, which do not seem to make an impact on flour? These raindrops probably exist but are not visible or they are very difficult to detect and measure with this methodology. Another limitation is the low frequency of the experimental measurements, which are not taken continuously during the rainfall event: disdrometers are needed to analyze continuous raindrop size during the whole rainfall event. But these limitations form part of the learning process which teachers should make clear to the students; with this in mind our experiment is perhaps most useful as an introduction to the study of rainfall processes.

In our experiment two different raindrop distributions were found by measuring raindrop size. When rainfall is produced by only one type of cloud, for example, weak precipitation due to stratiform clouds or heavy rainfall due to convective clouds, the DSD has only one peak, but two peaks were found in events where both types of cloud were present: this is more likely in late spring and early summer than in the other seasons in the Mediterranean climate of Barcelona. These two peaks in the fitted log-normal distribution have not been found in the scientific literature which uses this methodology. In all the studied cases, the frequency is well fitted by a one-peak log normal function, as described by several authors in different areas using more complicated and expensive methodologies: for example, Feingold and Levin (1986) in Israel, Cerro et al. (1998) in Barcelona, Yuter et al. (1996) in the Pacific area and Tokay et al. (1995) in several tropical areas.

Further research is suggested from this paper. In our experiment, the platform has been exposed to the raindrops up to three times for a few minutes after the precipitation event began. In order to analyse possible changes in DSD during the precipitation process, several platforms may be exposed several times, so as to analyse the DSD dependence on time during the whole precipitation event.

\section{Acknowledgement}

We express our gratitude to Daniel Crespo and David Pino for their help and suggestions. In addition, the comments of two reviewers helped us to improve the paper.

\section{References}

Bringi V, Huang G, Chandrasekar V Gorgucci E. 2003. A methodology for estimating the parameters of a gamma raindrop size distribution model from polarimetric radar data: application to a squall-line event from the TRMM/Brazil campaign. J. Atmos. Oceanic Technol. 19: 633-645.

Cerro C, Bech J, Codina B, Lorente J. 1998. Modeling rasin erosivity using disdrometric techniques. Soil Sci. Soc. Am. J. 62: 731-735.

Feingold G, Levin Z. 1986. The lognormal fit to raindrop spectra from frontal convective clouds in israel. J. Appl. Meteor. $\mathbf{2 5}$ 1346-1364.

Houze RA. 1993. Cloud Dynamics. Academic Press: San Diego, CA. 573 pp. Joss J, Gori E. 1978. Shapes of raindrop size distributions. J. Appl. Meteorol. 17: 1054-1061.

Kozu T, Nakamura K. 1991. Rain parameter estimation from dual- radar measurements combining reflectivity profile and path integrated attenuation. J. Atmos. Oceanic Technol. 8: 259-270.

Laws J, Parson DA. 1943. The relation of raindrop size to intensity. Trans. Am. Geophys. Union 24(II): 452-460.

Marshall JS, Palmer WM. 1948. The distribution of raindrops with size. J. Meteorol. 5: 165-166.

Radhakrishna B, Narayana R. 2008. Multipeak raindrop size distribution observed by UHF/VHF wind profilers during the passage of a mesoscale convective system. Am. Meteorol. Soc. 137: 976-990. doi:10.1175/2008MWR2607.1

Smith JA. 1993. Marked point process model distributions. J. Appl. Meteorol. 32 284-296.

Smith PL. 2003. Raindrop size distributions: exponential or gamma-Does the difference matter? J. Appl. Meteorol. 42 : 1031-1034.

Tokay A, Short D. 1995. Evidence from tropical raindrop spectra of the origin of rain from stratiform versus convective clouds. Am. Meteorol. Soc. 35: 351-377.

Ulbrich CW. 1983. Natural variations in the analytical form of the raindrop size distribution. J. Clim. Appl. Meteorol. 22 : 1764-1775.

Willis PT. 1984. Functional fits to some observed drop size distributions and parameterization of rain. J. Atmos. Sci. 41 : 1648-1661

Yuter S, Houze R. 1996. Measurements of raindrop size distributions over the pacific warm pool and implications for Z-R relations. Am. Meteorol. Soc. 36: 847-864

Zhang G, Vivekanandan J, Brandes E. 2001. A method for estimating rain rate and drop size distribution from polarimetric radarmeasurements. IEEE Trans. Geosci. Remote Sens. 39: 830-841.

\section{Correspondence to: Jordi Mazon}

\section{jordi.mazon@upc.edu}

(c) 2013 Royal Meteorological Society

DOI: 10.1002/wea.2064 